\title{
Long-term effect of bariatric surgery versus conventional therapy in obese Korean patients: a multicenter retrospective cohort study
}

\author{
Ji Yeon Park', Yoonseok Heo ${ }^{2,3}$, Yong Jin Kim 4,*, Joong-Min Park ${ }^{5}$, Seong-Min Kim ${ }^{6}$, Do-Joong Park ${ }^{7}$, \\ Sang Kuon Lee ${ }^{8}$, Sang-Moon Han ${ }^{9, *}$, Kyung-Won Shim ${ }^{10}$, Yeon Ji Lee ${ }^{11}$, Ja Youn Lee ${ }^{3}$, Jin-Won Kwon ${ }^{3,12}$ \\ ${ }^{1}$ Department of Surgery, Kyungpook National University Chilgok Hospital, School of Medicine, Kyungpook National University, \\ Daegu, Korea \\ ${ }^{2}$ Department of Surgery, Inha University School of Medicine, Incheon, Korea \\ ${ }^{3}$ National Evidence-based Healthcare Collaborating Agency, Seoul, Korea \\ ${ }^{4}$ Department of Surgery, Soonchunhyang University Seoul Hospital, Seoul, Korea \\ ${ }^{5}$ Department of Surgery, Chung-Ang University College of Medicine, Seoul, Korea \\ ${ }^{6}$ Department of Surgery, Gachon University College of Medicine, Incheon, Korea \\ ${ }^{7}$ Department of Surgery, Seoul National University Bundang Hospital, Seongnam, Korea \\ ${ }^{8}$ Department of Surgery, College of Medicine, The Catholic University of Korea, Seoul, Korea \\ ${ }^{9}$ Department of Surgery, CHA Gangnam Medical Center, CHA University School of Medicine, Seoul, Korea \\ ${ }^{10}$ Department of Family Medicine, Ewha Women's University School of Medicine, Seoul, Korea \\ ${ }^{11}$ Department of Family Medicine, Inha University School of Medicine, Incheon, Korea \\ ${ }^{12}$ College of Pharmacy, Kyungpook National University, Daegu, Korea
}

\begin{abstract}
Purpose: Long-term results following bariatric surgery compared to conventional treatments has never been reported in morbidly obese Korean patients. This study aimed to evaluate the long-term efficacy of bariatric surgery in morbidly obese Korean patients compared to conventional medical treatments.

Methods: In this multicenter retrospective cohort study, we reviewed 137 obese subjects between January 2008 and February 2011 with a body mass index (BMI) $>30 \mathrm{~kg} / \mathrm{m}^{2}$ who had more than 5 years of follow-up clinical data after bariatric surgery (surgery group, $\mathrm{n}=49$ ) or conventional treatment (conventional treatment group, $\mathrm{n}=88$ ). Anthropometric data and the status of comorbidities were compared between the 2 groups.

Results: The median follow-up period was 72.1 months (range 19.3-109.7 months). At the last follow-up, the surgery group showed a greater amount of total weight loss than the conventional treatment group $(24.9 \%$ vs. $2.8 \%, P<0.001)$. The prevalence of diabetes and hypertension significantly decreased in the surgery group, while the conventional treatment group showed a marked increase in these comorbidities. In the surgery group, Roux-en-Y gastric bypass and sleeve gastrectomy achieved comparable long-term weight loss (26.5\% vs. $22.4 \%$, respectively; $P=0.087$ ).

Conclusion: In the long-term, bariatric surgery achieved and maintained significantly greater weight reduction, as well as a decrease in obesity-related comorbidities, than did conventional medical therapy in morbidly obese Korean patients.

[Ann Surg Treat Res 2019;96(6):283-289]
\end{abstract}

Key Words: Morbid obesity, Bariatric surgery, Gastric bypass, Gastrectomy

Received November 29, 2018, Revised March 16, 2019,

Accepted April 1, 2019

Corresponding Author: Yong Jin Kim

Department of Surgery, Soonchunhyang University Seoul Hospital, 59

Daesagwan-ro, Yongsan-gu, Seoul 04401, Korea

Tel: +82-2-709-9479, Fax: +82-2-795-1687

E-mail: yjgs1997@gmail.com

ORCID code: https://orcid.org/0000-0003-1222-2121
*Current affiliation: Department of Surgery, LHK Bariatric and Metabolic Surgery Clinic, Seoul, Korea

Copyright (c) 2019, the Korean Surgical Society

(c) Annals of Surgical Treatment and Research is an Open Access Journal. All articles are distributed under the terms of the Creative Commons Attribution NonCommercial License (http://creativecommons.org/licenses/by-nc/4.0/) which permits unrestricted non-commercial use, distribution, and reproduction in any medium, provided the original work is properly cited. 


\section{INTRODUCTION}

Obesity is a growing health problem for most countries around the world and Korea is no exception [1]. According to a nationwide survey, the obese population (defined in Korea as a body mass index [BMI] of over $25 \mathrm{~kg} / \mathrm{m}^{2}$ ), has gradually increased over the last decade from $28.7 \%$ in 2006 to $32.4 \%$ in 2015 . The morbidly obese population, with a BMI of over $30 \mathrm{~kg} / \mathrm{m}^{2}$, has increased even more rapidly reaching $4.8 \%$ of the total population in 2015 ( $>800,000$ people), with the trend being more prominent in the younger generation $[2,3]$. Morbid obesity is associated with various comorbidities including: diabetes, dyslipidemia, cardiovascular diseases, fatty liver disease, and obstructive sleep apnea, etc., consequently shortening peoples' life spans. Medical expenditures associated with obesity were reported to be staggering and increased sharply with the growing incidence of obesity. Despite persistent efforts to control this obesity pandemic, none of the conservative measures, including medication, could successfully achieve long-lasting weight control.

Bariatric surgery is identified as an effective treatment for morbid obesity and leads to sustained weight loss, improvement of many obesity-related comorbidities and the quality of life and prolongs survival. The introduction of laparoscopic surgical techniques in the 1990s has accelerated advancements in bariatric and metabolic fields. This technology has significantly improved technical safety compared to the open surgical era and the number of procedures has exponentially increased 15 fold over the last two decades reaching 634,897 worldwide in 2016 [4,5]. Currently, bariatric surgery is one of the most commonly performed surgical procedures in the field of general surgery in the United States [6]. However, the number of procedures performed in Korea is still limited and the longterm results following bariatric surgery when compared with conventional treatments have never been reported in morbidly obese Korean patients.

This study aimed to evaluate the long-term efficacy of bariatric surgery in morbidly obese Korean patients compared with conventional medical treatments, using anthropometric and obesity-related comorbidity changes over a follow-up duration of more than 5 years.

\section{METHODS}

\section{Eligible patients}

Eligible patients were described in a previous 2012 retrospective study which investigated the short-term efficacy of bariatric surgery and included 261 surgical patients and 224 nonsurgical patients [7]. Briefly, the surgery group included all obese patients (BMI $>30 \mathrm{~kg} / \mathrm{m}^{2}$ ) who underwent consecutive bariatric surgeries at the surgical departments of 7 tertiary hospitals in Korea between January 2008 and February 2011. The conventional treatment group included patients who were managed with conventional therapies, which means intensive lifestyle modification accompanied by anorectic agents. Intensive lifestyle modification consisted of personalized nutritional education and physical training as well as the lifestyle coaching by obesity specialists at the departments of family medicine, which involved family medicine doctor, dietician and exercise practitioner. The relevant data of these patients were retrospectively collected via medical chart reviews.

The same cohort was used in the present study to evaluate the long-term outcomes (5-7 years) following bariatric surgery versus conservative treatment in patients with a BMI $>30 \mathrm{~kg} / \mathrm{m}^{2}$. Only 137 out of the eligible 485 patients in the previous study possessed sufficient follow-up clinical information for longterm result analyses. The cutoff date for the data collection was May 30th, 2017 in the present study. Approval for this review of hospital records was obtained from the Institutional Review Board of Inha University Hospital (IRB No. 2016-06-008-011), and the need for patient informed consent was waived.

\section{Data collection}

Baseline demographics and clinical characteristics including anthropometric data and past medical histories were collected a few days before each bariatric procedure in the surgery group, or at their first visit to initiate a weight management program in the conventional treatment group. Patients received a 3-month interval follow-up for 2 years, with longer intervals thereafter. Subsequent clinical data at each follow-up visit were retrospectively collected via chart reviews. The degree of weight loss was expressed as the percentage of total weight loss (\%TWL), which was calculated by dividing weight changes by the initial weight.

\section{Definition of obesity-related comorbidities}

The following definitions were used to define the obesityrelated comorbidities. Diabetes was defined as the use of antidiabetic medications, fasting blood glucose $\geq 126 \mathrm{mg} / \mathrm{dL}$, or hemoglobin $A_{1 c}$ level $\geq 6.5 \%$. Hypertension was defined as the use of antihypertensive medications, systolic blood pressure $\geq 140 \mathrm{mmHg}$, or diastolic blood pressure $\geq 90 \mathrm{mmHg}$. Dyslipidemia was defined as the used lipid-lowering agents, total cholesterol $\geq 240 \mathrm{mg} / \mathrm{dL}$, triglycerides $\geq 200 \mathrm{mg} / \mathrm{dL}$, or low-density lipoprotein cholesterol $\geq 160 \mathrm{mg} / \mathrm{dL}$. The prevalence of the disease at baseline and at the final followup was calculated based on these definitions and compared between the groups.

\section{Statistical analyses}

Statistical analyses were performed using IBM SPSS ver. 18.0 
(IBM Co., Armonk, NY, USA). Means with standard deviation or medians with ranges of the variables were calculated and compared between groups. The chi-square test or Fisher exact test was applied to analyze categorical variables, while the Student t-test was used for continuous variables. All tests were two-tailed and $\mathrm{P}<0.05$ were considered significant.

\section{RESULTS}

Eighty-eight patients in the conventional group and 49 patients in the surgery group were included in the present study. In the surgery group, the primary bariatric procedure was laparoscopic sleeve gastrectomy (SG, $n=19$ ) or Roux-en-Y gastric bypass (RYGB, $n=30$ ). The baseline characteristics of the 137 patients are shown in Table 1. The surgery group had significantly more females $(77.6 \%$ vs. $58.0 \%, \mathrm{P}=0.021)$ and was also significantly younger compared to the nonsurgical group (38.1 years vs. 41.6 years, $P=0.021$ ). At baseline, the surgery group had a higher BMI than those who received conservative treatments $\left(39.0 \pm 7.0 \mathrm{~kg} / \mathrm{m}^{2}\right.$ vs. $\left.33.6 \pm 3.1 \mathrm{~kg} / \mathrm{m}^{2}, \mathrm{P}<0.001\right)$.

The median follow-up period for all patients was 72.1 months (range 19.3-109.7 months) as shown in Table 2. At the last follow-up, patients in the surgery group demonstrated weight loss of $27.1 \pm 14.6 \mathrm{~kg}$ which was significantly greater than the $2.7 \pm 7.3 \mathrm{~kg}$ weight loss in the conventional group ( $\mathrm{P}<$ 0.001 ). The results correspond to a $24.9 \%$ versus $2.8 \%$ reduction of the initial total body weight in each group, which was markedly superior in the surgery group ( $P<0.001)$. A closer look at the data revealed that 31 out of 88 patients (35.2\%) in the conventional group showed paradoxical weight gain at the last follow-up in comparison with the baseline. In spite of conservative weight management efforts they showed, on

Table 1. Baseline patient characteristics

\begin{tabular}{lccc}
\hline \multicolumn{1}{c}{ Characteristic } & $\begin{array}{c}\text { Conventional } \\
\text { therapy group } \\
(\mathrm{n}=88)\end{array}$ & $\begin{array}{c}\text { Surgery } \\
\text { group } \\
(\mathrm{n}=49)\end{array}$ & P-value \\
\hline Age $(\mathrm{yr})$ & $41.6 \pm 12.7$ & $38.1 \pm 11.7$ & 0.113 \\
Sex & $37(42.0)$ & $11(22.4)$ & 0.021 \\
$\quad$ Male & $51(58.0)$ & $38(77.6)$ & \\
$\quad$ Female & $90.7 \pm 14.2$ & $106.4 \pm 25.2$ & $<0.001$ \\
Body weight $(\mathrm{kg})$ & $33.6 \pm 3.1$ & $39.0 \pm 7.0$ & $<0.001$ \\
Body mass index $\left(\mathrm{kg} / \mathrm{m}^{2}\right)$ & $64(72.7)$ & $17(34.7)$ & \\
$\quad 30-34.9$ & $21(23.9)$ & $16(32.7)$ & \\
$35-39.9$ & $3(3.4)$ & $16(32.7)$ & \\
$\geq 40$ & $12(18.8)^{\mathrm{b})}$ & $6(14.3)^{\mathrm{b})}$ & 0.373 \\
Smoking & $31(49.2)^{\mathrm{b})}$ & $10(20.8)^{\mathrm{b})}$ & 0.002 \\
Alcohol consumption & $13(24.5)^{\mathrm{b})}$ & $19(45.2)^{\mathrm{b})}$ & 0.034 \\
Unmarried $^{\text {and }}$ & & & \\
\hline
\end{tabular}

Values are presented as mean \pm standard deviation or number $(\%)$. ${ }^{\text {a) }}$ Current smoker + past smoker. ${ }^{\text {b) }}$ The percentage among patients with available data. average, a 4.2-kg body weight increase during the follow-up period. Patient weight increase after surgical treatment did not occur although the amount of weight loss varied among patients. Chronological changes of body weight showed that a patient's maximum weight loss occurred between 12 and 18 months after initiation of the treatment for both groups (Fig. 1). Patients in the conventional treatment group achieved a maximum weight loss of $8.6 \mathrm{~kg}(8.7 \%$ in \%TWL) 12 months following the initiation of weight management and then showed slow but steady regain of body weight thereafter. They ultimately regained more than half of their total weight lost despite constant efforts to control body weight over the following years. Meanwhile, patients in the surgery group reached their nadir weight at $12-18$ months after surgery with weight loss up to $32.3 \mathrm{~kg}$ (27.2\% in \%TWL) and maintained their reduced body weight up to 3 to 5 years without significant weight regain.

The prevalence of obesity-related comorbidities is shown in Table 3. At baseline, type 2 diabetes was more prevalent in the surgery group $(51.0 \%)$ than in the conventional treatment group (13.6\%, $\mathrm{P}<0.001$ ). However, the prevalence of diabetes reversed at the last follow-up, which showed an increase in the conventional treatment group compared to the marked decrease in the surgery group. Similarly, the prevalence of hypertension markedly decreased from $65.3 \%$ to $24.5 \%$ following the surgery, while it increased from $44.3 \%$ to $53.4 \%$ for those receiving conventional therapy. The prevalence of dyslipidemia decreased in both groups, but the surgery group demonstrated a sharper drop than the conventional treatment group.

The surgery group was comprised of 30 RYGB patients and 19 SG patients. The baseline BMI was significantly higher in SG patients $\left(42.0 \pm 7.9 \mathrm{~kg} / \mathrm{m}^{2}\right)$ than in RYGB patients $(37.1 \pm 5.8$ $\mathrm{kg} / \mathrm{m}^{2}, \mathrm{P}=0.011$ ) (Table 4). At the last follow-up, patients lost $26.5 \%$ total body weight following RYGB and $22.4 \%$ following

Table 2. Anthropometric outcomes at the last follow-up

\begin{tabular}{lccr}
\hline \multicolumn{1}{c}{ Variable } & $\begin{array}{c}\text { Conventional } \\
\text { therapy group } \\
(\mathrm{n}=88)\end{array}$ & $\begin{array}{c}\text { Surgery } \\
\text { group } \\
(\mathrm{n}=49)\end{array}$ & P-value \\
\hline Follow-up $(\mathrm{mo})$ & $73.7(53.4-87.2)$ & $71.0(50.1-75.2)$ & 0.056 \\
$\Delta$ Body weight $(\mathrm{kg})^{\text {a) }}$ & $2.7 \pm 7.3$ & $27.1 \pm 14.6$ & $<0.001$ \\
$\Delta \mathrm{BMI}\left(\mathrm{kg} / \mathrm{m}^{2}\right)^{\mathrm{a})}$ & $1.0 \pm 2.8$ & $9.9 \pm 5.2$ & $<0.001$ \\
$\% \mathrm{TWL}(\%)^{\mathrm{b})}$ & $2.8 \pm 8.0$ & $24.9 \pm 9.6$ & $<0.001$ \\
Weight change & & & \\
status & $57(64.8)$ & $49(100)$ & $<0.001$ \\
$\quad$ Weight loss & $31(35.2)$ & $0(0)$ & \\
\hline Weight gain & & & \\
\hline
\end{tabular}

Values are presented as median (interquartile range), mean \pm standard deviation, or number (\%).

$\mathrm{BMI}$, body mass index; \%TWL, percent of total weight loss.

${ }^{\text {a) }}$ Positive value indicates reduced amount. ${ }^{\text {b) }} \% \mathrm{TWL}=\Delta$ Body weight/baseline body weight $\times 100$. 
A

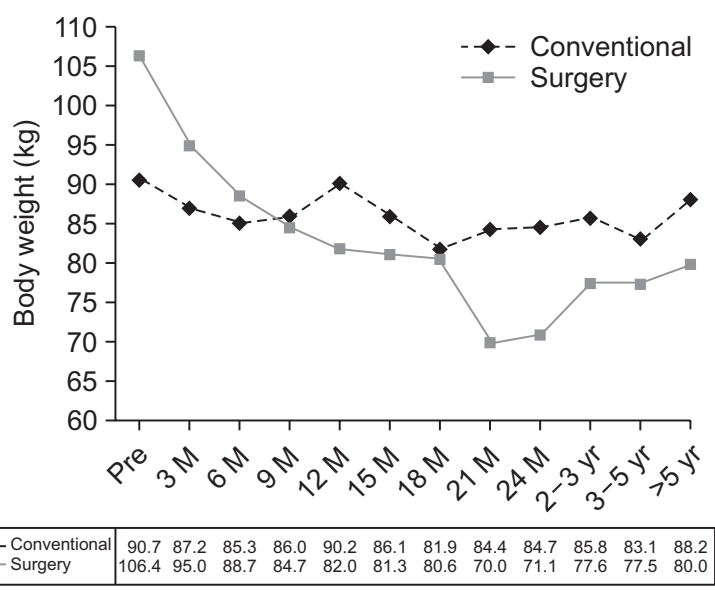

C

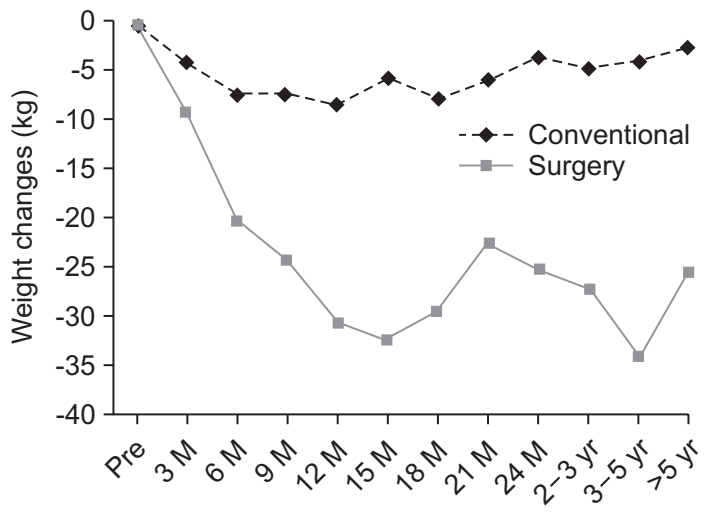

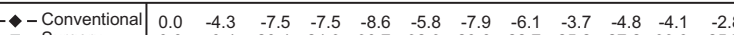

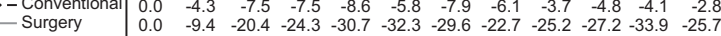

B

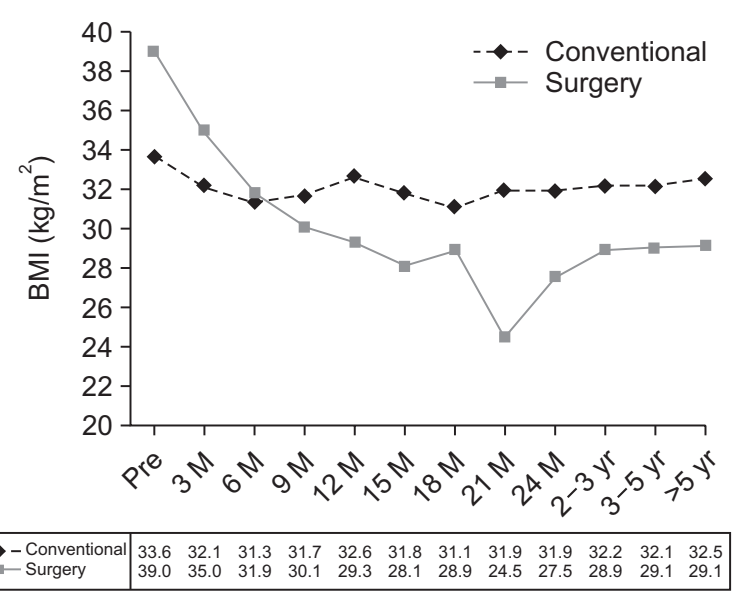

D

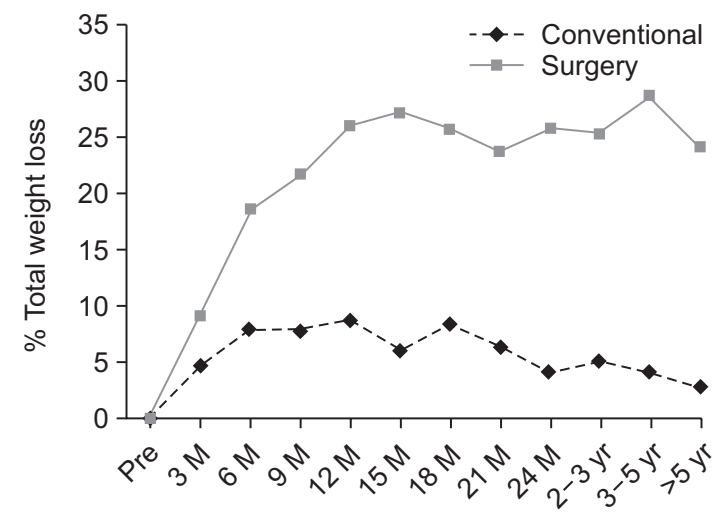

\begin{tabular}{l|rrrrrrrrrrrr|}
-- - Conventional & 0.0 & 4.7 & 8.0 & 7.8 & 8.7 & 6.0 & 8.4 & 6.4 & 4.1 & 5.0 & 4.1 & 2.8 \\
- - Surgery & 0.0 & 9.1 & 18.5 & 21.8 & 26.1 & 27.2 & 25.8 & 23.8 & 25.9 & 25.4 & 28.7 & 24.1 \\
\hline
\end{tabular}

Fig. 1. Weight and body mass index changes during the follow-up period in both groups (M, months). Body weight (kg) (A), body mass index $\left(\mathrm{BMI}, \mathrm{kg} / \mathrm{m}^{2}\right)(\mathrm{B})$, weight changes $(\mathrm{kg})(\mathrm{C})$, and percent of total weight loss $(\% \mathrm{TWL})(\mathrm{D})$.

Table 3. Changes in the incidence of obesity-related comorbidities

\begin{tabular}{lccr}
\hline & $\begin{array}{c}\text { Conventional } \\
\text { therapy group } \\
(\mathrm{n}=88)\end{array}$ & $\begin{array}{c}\text { Surgery } \\
\text { group } \\
(\mathrm{n}=49)\end{array}$ & P-value $^{\mathrm{a})}$ \\
\hline Diabetes & $12(13.6)$ & $25(51.0)$ & $<0.001$ \\
$\quad$ Baseline & $22(25.0)$ & $16(32.7)$ & 0.370 \\
Last follow-up & $39(44.3)$ & $32(65.3)$ & 0.018 \\
Hypertension & $47(53.4)$ & $12(24.5)$ & 0.001 \\
$\quad$ Baseline & & & \\
$\quad$ Last follow-up & $39(44.3)$ & $17(34.7)$ & 0.272 \\
$\begin{array}{c}\text { Dyslipidemia } \\
\text { Baseline }\end{array}$ & $37(42.0)$ & $4(8.2)$ & $<0.001$ \\
Last follow-up & 37 & \\
\hline
\end{tabular}

Values are presented as number (\%).

${ }^{\text {a) }}$ Pearson chi-square test.

SG; the difference was marginally significant $(P=0.087)$. The chronological changes of body weight and \%TWL demonstrated a similar pattern of weight loss without a statistically significant difference between the 2 procedures (Fig. 2).

Eight out of 19 SG patients (42.1\%) required revisional surgery during the follow-up period and all of them were converted to RYGB. The specific causes for the conversion were as follows: 3 patients for intractable gastroesophageal reflux, 2 for poorlycontrolled diabetes, 2 for insufficient weight loss, and 1 for gastric tube stricture.

\section{DISCUSSION}

The present study demonstrated that the efficacy of bariatric surgery was superior to conventional therapy in terms of longterm weight reduction and maintenance. This study was an extension of a previous study which compared the shortterm efficacy of bariatric surgery compared to medical therapy in weight and comorbidity management in morbidly obese Koreans. Prolonged follow-up of this identical cohort showed that the patients in the surgical group successfully maintained their weight loss for over 5-7 years compared to those in the conventional treatment group who showed slow weight regain 
after the first year of enrollment in the weight management program. To our knowledge, this is the first Korean report which addresses the long-term outcomes in morbidly obese patients undergoing bariatric surgery versus those receiving conventional medical treatments.

Over the last several decades, numerous studies have already clearly demonstrated the short-term superiority of bariatric surgery over conventional weight management therapy which includes the previous Korean multicenter study [7]. However, evidence for long-term surgical efficacy has not been evaluated to a great extent, since a substantial proportion of the patients

Table 4. Comparison of the baseline characteristics and surgical outcomes following Roux-ne-Y gastric bypass vs. sleeve gastrectomy

\begin{tabular}{lccc}
\hline \multicolumn{1}{c}{ Variable } & $\begin{array}{c}\text { RYGB } \\
(\mathrm{n}=30)\end{array}$ & $\begin{array}{c}\text { SG } \\
(\mathrm{n}=19)\end{array}$ & P-value $^{\mathrm{a})}$ \\
\hline $\begin{array}{l}\text { Age }(\mathrm{yr}) \\
\text { Sex }\end{array}$ & $40.2 \pm 12.9$ & $34.7 \pm 8.8$ & 0.234 \\
$\quad$ Male & $6(20.0)$ & $5(26.3)$ & $0.729^{\mathrm{b})}$ \\
$\quad$ Female & $24(80.0)$ & $14(73.7)$ & \\
Baseline body weight & $100.7 \pm 23.4$ & $115.3 \pm 25.9$ & 0.029 \\
Baseline BMl & $37.1 \pm 5.8$ & $42.0 \pm 7.9$ & 0.011 \\
At last follow-up & & & \\
$\quad$ Follow-up duration & $63.1 \pm 19.4$ & $66.4 \pm 19.4$ & 0.535 \\
$\quad($ mo) & & & \\
$\quad \Delta$ Body weight (kg) & $27.3 \pm 13.1$ & $26.7 \pm 17.1$ & 0.545 \\
$\quad \begin{array}{l}\left.\text { BMI (kg/m }{ }^{2}\right) \\
\text { \%TWL }(\%)\end{array}$ & $10.0 \pm 4.4$ & $9.7 \pm 6.3$ & 0.356 \\
Revisional surgery & $26.5 \pm 8.9$ & $22.4 \pm 10.4$ & 0.087 \\
& $1(3.3)$ & $8(42.1)$ & $0.001^{\mathrm{b})}$ \\
\hline
\end{tabular}

Values are presented as mean \pm standard deviation or number (\%).

RYGB, Roux-en-Y gastric bypass; SG, sleeve gastrectomy; BMI, body mass index; \%TWL, percent of total weight loss.

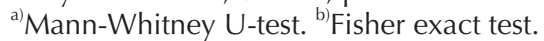

are usually lost to follow-up within a few years after bariatric surgery. It is difficult to discuss the prolonged benefit of bariatric surgery without referring to the monumental Swedish Obese Subjects study, which is a prospective, interventional, case-controlled study designed to elucidate the long-term effects of bariatric surgery in comparison with medical treatments [8]. Although some of the surgical procedures adopted in that study are now no longer in use, the study is still ongoing and has followed the recruited obese subjects for more than 10-15 years, producing voluminous results [9]. They dealt with a wide range of health issues related to obesity which demonstrated the superiority of surgical intervention over conventional therapies in terms of sustained weight loss and its association with lower mortality, resolution of comorbidities, occurrence of de novo diabetes or other metabolic and malignant diseases, health-related quality of life, and socio-economic aspects [10-14]. Other representative randomized controlled trials comparing surgical versus medical therapy have shown similar results demonstrating significantly greater weight reduction along with better glycemic control in the surgical group $[15,16]$. These studies uniformly revealed that the surgical patients reached their nadir weight at 1-2 years followed by slight weight regain in subsequent years. Although the efficacy varied depending on the type of procedures used, bariatric surgery achieved $14 \%-$ $31 \%$ of total weight loss after 5 years or more compared to the minimal changes following conventional treatments. This is consistent with weight trajectories shown in the present study among Korean patients with comparable weight loss in the surgery group (24.9\%) at the median follow-up of 73.7 months.

Regarding obesity-related comorbidities, our data was insufficient to be able to delineate whether the patients with diabetes, hypertension, or dyslipidemia at baseline experienced remission or relapse over time following each treatment. Instead, only the prevalence of each disease at baseline and

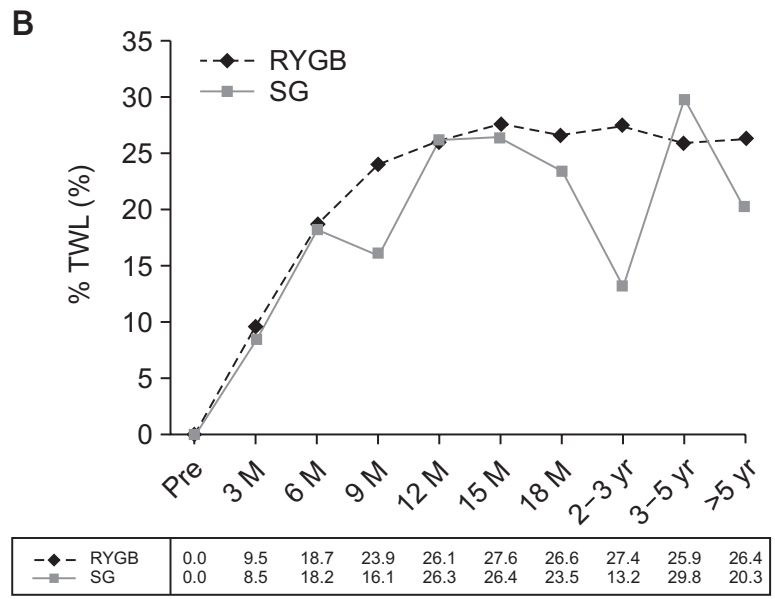

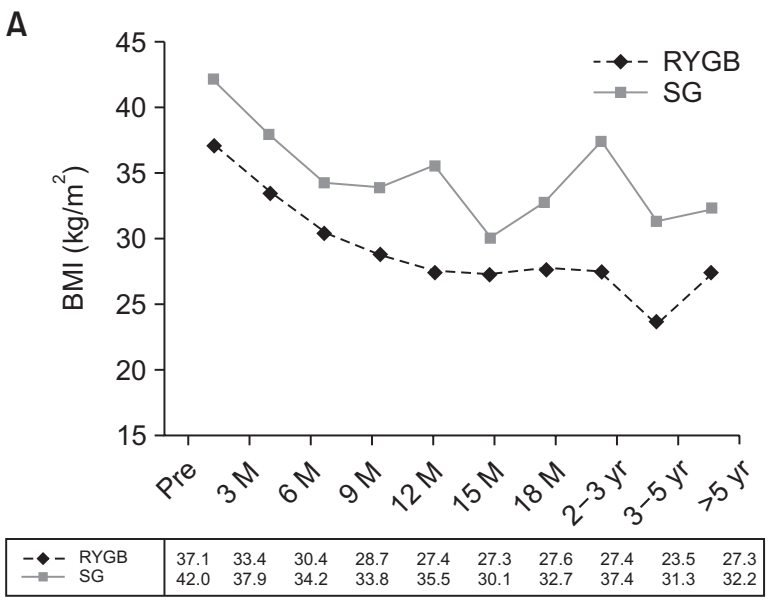

Fig. 2. Anthropometric chronological changes following Roux-en-Y gastric bypass (RYGB) versus sleeve gastrectomy (SG). Body mass index $\left(\mathrm{BMI}, \mathrm{kg} / \mathrm{m}^{2}\right)(\mathrm{A})$ and percent of total weight loss (\%TWL) (B). M, month. 
then at the final follow-up was available. At baseline, the surgery group showed a significantly higher prevalence of diabetes and hypertension along with a higher baseline BMI. A prominent decrease in the prevalence of all diseases was then observed in the surgery group, while a paradoxical increase or minor change was detected between the 2 time points in the conventional treatment group despite the weight management effort. This indirectly reflects the superior efficacy of bariatric surgery in either remission or prevention of the diseases associated with obesity and corresponds with the results from previous studies $[9,15,16]$.

In the present study, RYGB seemed to achieve a higher \%TWL than SG in the long term, but the difference was not statistically significant. The result is in agreement with 2 previous randomized clinical trials published this year which compared SG with RYGB. They shared a very similar study protocol and both studies concluded that there was no statistical difference in the percentage of excess weight loss 5 years following the 2 surgical procedures, although gastric bypass appeared numerically slightly better over time [17,18]. The revision rate after SG in the present study was $42.1 \%$, which was strikingly higher than those reported in previous prospective studies (8.4\%-14.9\%), even taking into account the learning curve effect. One thing to be reminded here is that the reported incidence of complications was $21.9 \%$ and $12.1 \%$ following RYGB and SG, respectively, during the median follow-up of 9 months in the original study using the same cohort, which included 73 RYGB and 116 SG patients [7]. Therefore, the result in the present study should be interpreted with caution, because the attrition rate is considerably high and the patients with intractable surgical side effects may have been selectively retained to the final follow-up. Nonetheless, the present study and the aforementioned 2 randomized controlled trials consistently revealed that the most discouraging drawback of SG was exacerbation or de novo development of the gastroesophageal reflux disease (GERD). Intolerable GERD was the most common reason for reoperation after SG, accounting for $6.0 \%$ to $15.8 \%$ of all SG patients.

The most concerning and frustrating problem in the present study is that a substantial proportion of the patients were lost to follow-up after 5 years with the overall attrition rate reaching $71.8 \%$. Interestingly, the surgical group showed poorer adherence to the postoperative follow-up instructions with an attrition rate of $81.2 \%$ compared to the conservative treatment group (attrition rate of $60.7 \%$ ). This phenomenon was already documented in previous studies indicating that bariatric patients usually showed poor compliance for follow-up visits [19]. Since adherence to follow-up is known to induce better weight loss outcomes and is also strongly recommended for long-term patient safety, an effective and practical follow-up care plan is required at bariatric centers [20-22]. Aarts et al. [23], suggested that more personalized care catering to individual patient needs, which included allowing follow-up on a more ad hoc basis via easily accessible platforms such as e-mail, phone, or primary physicians, rather than an attendance-based model for regular monitoring, would reduce attrition rates.

In Korea, the present study made it clear that it is no longer debatable whether medical treatment or surgery is more effective in managing morbid obesity. It is time to move forward by encouraging collaboration among multidisciplinary teams in order to provide an optimal therapeutic plan to achieve sustainable weight reduction as well as comorbidity control and it should be tailored to the needs of individual patients.

There are some critical limitations in the present study. First, it was a retrospective study basically relying on chart reviews and the patients were not randomly assigned to the surgery or the conventional treatment group, posing an inherent risk of selection bias. Secondly, the number of included patients became markedly small compared to the original short-term study, owing to the high attrition rate. The number of surgical patients included in the chronological data analyses was even smaller, particularly between 18 months and 3-5 year of followup, which resulted in an abrupt increase or decrease in the \%TWL trajectories causing confusion in the interpretation. This high attrition rate may also imply the possibility that only patients with good treatment results were selected, while those with poor outcomes were largely lost to follow-up and excluded in the final analysis. As Puzziferri et al. [19], have pointed out in a previous review, this extent of attrition could cause distortion in data interpretation, and consequently make it difficult to draw a concrete conclusion based on the present study. Therefore, in the future, a well-designed prospective study with acceptable retention rates is required to clearly elucidate the long-term effects of bariatric surgery and to facilitate an optimal therapeutic decision for Korean patients with morbid obesity.

In conclusion, over the long-term, bariatric surgery achieved and maintained significantly greater weight reduction, as well as a decrease in obesity-related comorbidities, than did conventional medical therapies in morbidly obese Korean patients.

\section{CONFLICTS OF INTEREST}

No potential conflict of interest relevant to this article was reported.

\section{ACKNOWLEDGEMENTS}

This work was supported by grants from the Korean Health Technology R\&D Project (HC15C1322), Ministry of Health \& Welfare, Republic of Korea (for YH). 
1. World Health Organization. Obesity and overweight fact sheets [Internet]. Geneva (Switzerland): World Health Organization; c2019 [2018 Oct 10]. Available from: http:// www.who.int/news-room/fact-sheets/ detail/obesity-and-overweight.

2. National Health Insurance Service. National Health Information Database [Internet]. Wonju (Korea): National Health Insurance Service; c2014 [2018 Oct 10]. Available from: https://nhiss.nhis.or.kr/ bd/ay/bdaya001iv.do.

3. Shin HY, Kang HT. Recent trends in the prevalence of underweight, overweight, and obesity in Korean adults: The Korean National Health and Nutrition Examination Survey from 1998 to 2014. J Epidemiol 2017;27:413-9.

4. Wittgrove AC, Clark GW, Tremblay LJ. Laparoscopic gastric bypass, roux-en-Y: preliminary report of five cases. Obes Surg 1994:4:353-7.

5. Scopinaro N. The IFSO and obesity surgery throughout the world. International Federation for the Surgery of Obesity. Obes Surg 1998;8:3-8.

6. Pierce J, Galante J, Scherer LA, Chang EJ, Wisner D, Ali M. PL-202: bariatric surgery in the balance: a paradigm shift in general surgery. Surg Obes Relat Dis 2010; 6(3 Suppl):S10.

7. Heo YS, Park JM, Kim YJ, Kim SM, Park DJ, Lee SK, et al. Bariatric surgery versus conventional therapy in obese Korea patients: a multicenter retrospective cohort study. J Korean Surg Soc 2012;83:335-42.

8. Sjostrom L, Larsson B, Backman L, Bengtsson C, Bouchard C, Dahlgren S, et al. Swedish obese subjects (SOS). Recruitment for an intervention study and a selected description of the obese state. Int J Obes Relat Metab Disord 1992;16:465-79.
9. Sjostrom L. Review of the key results from the Swedish Obese Subjects (SOS) trial - a prospective controlled intervention study of bariatric surgery. J Intern Med 2013; 273:219-34.

10. Sjostrom L, Narbro K, Sjostrom CD, Karason K, Larsson B, Wedel H, et al. Effects of bariatric surgery on mortality in Swedish obese subjects. N Engl J Med 2007:357:741-52.

11. Sjostrom L, Gummesson A, Sjostrom CD, Narbro K, Peltonen M, Wedel H, et al. Effects of bariatric surgery on cancer incidence in obese patients in Sweden (Swedish Obese Subjects Study): a prospective, controlled intervention trial. Lancet Oncol 2009;10:653-62.

12. Sjostrom L, Peltonen M, Jacobson P, Ahlin S, Andersson-Assarsson J, Anveden A, et al. Association of bariatric surgery with long-term remission of type 2 diabetes and with microvascular and macrovascular complications. JAMA 2014;311: 2297-304

13. Sjostrom L, Peltonen M, Jacobson P, Sjostrom CD, Karason K, Wedel H, et al. Bariatric surgery and long-term cardiovascular events. JAMA 2012;307:56-65.

14. Carlsson LM, Peltonen M, Ahlin S, Anveden A, Bouchard C, Carlsson B, et al. Bariatric surgery and prevention of type 2 diabetes in Swedish obese subjects. N Engl J Med 2012;367:695-704.

15. Mingrone G, Panunzi S, De Gaetano A, Guidone C, Iaconelli A, Nanni G, et al. Bariatric-metabolic surgery versus conventional medical treatment in obese patients with type 2 diabetes: 5 year follow-up of an open-label, single-centre, randomised controlled trial. Lancet 2015;386:964-73.

16. Schauer PR, Bhatt DL, Kirwan JP, Wolski K, Aminian A, Brethauer SA, et al. Bariatric surgery versus intensive medical therapy for diabetes - 5-year outcomes. N Engl J Med 2017;376:641-51.

17. Peterli R, Wolnerhanssen BK, Peters T, Vetter D, Kroll D, Borbély Y, et al. Effect of laparoscopic sleeve gastrectomy vs laparoscopic roux-en-Y gastric bypass on weight loss in patients with morbid obesity: the SM-BOSS randomized clinical trial. JAMA 2018:319:255-65.

18. Salminen P, Helmio M, Ovaska J, Juuti A, Leivonen $\mathrm{M}$, Peromaa-Haavisto $\mathrm{P}$, et al. Effect of laparoscopic sleeve gastrectomy vs laparoscopic roux-en-Y gastric bypass on weight loss at 5 years among patients with morbid obesity: the SLEEVEPASS randomized clinical trial. JAMA 2018;319: 241-54.

19. Puzziferri N, Roshek TB 3rd, Mayo HG, Gallagher R, Belle SH, Livingston EH. Long-term follow-up after bariatric surgery: a systematic review. JAMA 2014;312: 934-42.

20. Schwoerer A, Kasten K, Celio A, Pories W, Spaniolas K. The effect of close postoperative follow-up on co-morbidity improvement after bariatric surgery. Surg Obes Relat Dis 2017;13:1347-52.

21. Gould JC, Beverstein G, Reinhardt S, Garren MJ. Impact of routine and longterm follow-up on weight loss after laparoscopic gastric bypass. Surg Obes Relat Dis 2007:3:627-30.

22. Compher CW, Hanlon A, Kang Y, Elkin L, Williams NN. Attendance at clinical visits predicts weight loss after gastric bypass surgery. Obes Surg 2012:22:927-34.

23. Aarts MA, Sivapalan N, Nikzad SE, Serodio K, Sockalingam S, Conn LG. Optimizing bariatric surgery multidisciplinary followup: a focus on patient-centered care. Obes Surg 2017;27:730-6. 